\title{
A novel hydroxamic acid derivative, MHY218, induces apoptosis and cell cycle arrest through downregulation of NF-kB in HCT116 human colon cancer cells
}

\author{
MI KYEONG KIM ${ }^{1 *}$, YONG JUNG KANG ${ }^{1 *}$, DONG HWAN KIM ${ }^{1}$, MOHAMMAD AKBAR HOSSAIN $^{1,2}$, \\ JUNG YOON JANG ${ }^{1}$, SUN HWA LEE ${ }^{1}$, JEONG-HYUN YOON ${ }^{1}$, PUSOON CHUN ${ }^{3}$, HYUNG RYONG MOON ${ }^{1}$, \\ HYUNG SIK KIM ${ }^{4}$, HAE YOUNG CHUNG ${ }^{1}$ and NAM DEUK KIM ${ }^{1}$ \\ ${ }^{1}$ Division of Pharmacy, College of Pharmacy, Molecular Inflammation Research Center for Aging Intervention (MRCA), \\ Pusan National University, Busan 609-735, Republic of Korea; ${ }^{2}$ Department of Pharmacology and Toxicology, \\ Faculty of Pharmacy, Umm Al-Qura University, Makkah, Kingdom of Saudi Arabia; ${ }^{3}$ College of Pharmacy, \\ Inje University, Gimhae, Gyeongnam 621-749; ${ }^{4}$ Division of Toxicology, College of Pharmacy, \\ Sungkyunkwan University, Suwon, Gyeonggi-do, Republic of Korea
}

Received July 22, 2013; Accepted October 14, 2013

DOI: $10.3892 /$ ijo.2013.2163

\begin{abstract}
Colorectal cancer (CRC) is one of the most common malignant diseases and frequent cause of cancer deaths in the world. In spite of the significant advances in conventional therapeutic approaches to $\mathrm{CRC}$, most patients ultimately die of their disease. There is a need to develop novel preventive approaches for this malignancy. This study was carried out to investigate the anticancer effect of MHY218, a hydroxamic acid derivative, in HCT116 human colon cancer cells. Treatment of cells with MHY218 resulted in growth inhibition and induction of apoptosis in a concentration-dependent manner. MHY218 induced $\mathrm{G} 2 / \mathrm{M}$ phase arrest in the cell cycle progression which was observed by flow cytometry analysis, and a decrease in the protein expression of cyclin $\mathrm{B} 1$ and its activating partners Cdc25C and Cdc2. MHY218 also caused an increase in the expression levels of $\mathrm{p} 21^{\text {WAFI/CIPI }}$, a G2/M phase inhibitor, in a p53-independent pathway. The induction of apoptosis was observed by decreased viability, DNA fragmentation, cleavage of poly(ADP-ribose) polymerase, alteration in the ratio of Bax/Bcl-2 protein expression, and activation of caspase-3, -8 and -9 . In addition, MHY218 treatment showed downregulation of the expression levels of the transcription factor nuclear factor-kappa $\mathrm{B}(\mathrm{NF}-\kappa \mathrm{B})$ in the nucleus, which has been reported to be implicated in the apoptotic cell death of several
\end{abstract}

Correspondence to: Dr Nam Deuk Kim, Division of Pharmacy, College of Pharmacy, Pusan National University, 63 Beon-gil 2, Busandaehag-ro, Geumjeong-gu, Busan 609-735, Republic of Korea E-mail: nadkim@pusan.ac.kr

${ }^{*}$ Contributed equally

Key words: hydroxamic acid derivative, colon cancer cells, apoptosis, cell cycle, $\mathrm{NF}-\kappa \mathrm{B}$ types of cancer cells, suppression of TNF- $\alpha$-induced NF- $\kappa \mathrm{B}$ activation, inhibition of cyclooxygenase- 2 expression, repression of matrix metalloproteinase- 9 activation and decrease of 5-lipoxygenase in a concentration-dependent manner. These results suggest that MHY218 may be a useful candidate to be used in the chemoprevention and/or treatment of colon cancer.

\section{Introduction}

Colorectal cancer (CRC) is a cancer from uncontrolled cell growth in the lining of the large intestine, such as colon and rectum. CRC is the fourth most common cancer in the world, but it is more common in developed countries. CRC is the third most common cancer and the fourth leading cause of cancer-related death in Korea and the incidence of CRC have been increased rapidly over the past few decades $(1,2)$. While surgical resection cures $>50 \%$ of CRC patients, $40-50 \%$ of these subjects eventually experience recurrences, leaving only a minority amenable to re-operation (3). Because of unsatisfactory treatment options for CRC, there is an urgent need to develop novel preventive treatment approaches for this malignancy.

Progressive inhibition or evasion of apoptosis has been found during the transformation of colorectal epithelium to carcinoma (4), indicating that dysfunction of apoptosis has important roles in colorectal carcinogenesis. The cytotoxic action of most chemotherapeutic drugs is often mediated by the activation of apoptotic pathways (5). Recent progress in understanding the molecular mechanisms and role of apoptosis in CRC development has provided novel targets for therapy.

Nuclear factor- $\kappa \mathrm{B}(\mathrm{NF}-\kappa \mathrm{B})$, a transcription factor, controls the expression of genes involved in tumor cell growth, proliferation, angiogenesis, invasion and survival. NF- $\kappa \mathrm{B}$ is composed of two subunits, p65 and p50, and is normally sequestered in the cytosol by an inhibitory protein, IкB $\alpha$. Exposure of cells to a variety of extracellular stimuli leads to the rapid phosphorylation, ubiquitination, and ultimately 
proteolytic degradation of $\mathrm{I} \kappa \mathrm{B} \alpha$, resulting in the release of $\mathrm{NF}-\kappa \mathrm{B}$ from its inhibitory protein to translocate to the nucleus where it regulates transcription of various genes (6). Increased $\mathrm{NF}-\kappa \mathrm{B}$ activity has been demonstrated in colon cancer, which is believed to enhance cancer cell survival by inhibiting apoptosis. In addition, the inflammatory colon diseases such as Crohn's disease and ulcerative colitis are associated with the constitutive activation of $N F-\kappa B(7)$. Inhibition of $N F-\kappa B$ in cancer cells converts inflammation-induced tumor growth to inflammation-induced tumor regression mediated by TNF- $\alpha$ and TRAIL (8). Therefore, inhibition of NF- $\kappa B$ signaling pathway provides attractive targets for new chemopreventive and chemotherapeutic approaches.

Hydroxamic acids are known as iron chelators and microbial siderophores that show diverse biological activities such as antibacterial, antifungal, antitumor and anti-inflammatory properties (9). Some hydroxamates, such as suberoylanilide hydroxamic acid, has been used clinically for the treatment of cancer (10). For the purpose of creating more effective antitumor drugs many derivatives that possess the hydroxamic acid functional group were synthesized (11). The newly designed hydroxamic acid derivatives have been shown to have anticancer effect in various cancer cells (12). MHY218 [ $\mathrm{N}^{1}$-hydroxy- $\mathrm{N}^{8}$-(4-phenoxyphenol)octanedianide] was synthesized and it was a novel hydroxamic acid derivative. MHY218 has inhibitory activity of histone deacetylase and anticancer effects against human ovarian cancer cells (13) and tamoxifen-resistant MCF-7 breast cancer cells (14). The chemical structures of hydroxamic acids and MHY218 are shown in Fig. 1. However, the effects of MHY218 were not studied in HCT116 human colon cancer cells in previous reports. Therefore, the main purpose of this study was to focus on investigating the effects of MHY218 on cell cycle and apoptosis in HCT116 human colon cancer cells.

\section{Materials and methods}

Chemicals. The simplified code name and structure of MHY218 [ $\mathrm{N}^{1}$-hydroxy-N $\mathrm{N}^{8}$-(4-phenoxyphenol)octanedianide] used in this study is shown in Fig. 1B. Detailed method for the design and synthesis of this compound is described elsewhere (13). This was dissolved in sterile dimethyl sulfoxide (DMSO) to generate $10 \mathrm{mM}$ stock solution. The solutions were stored at $-80^{\circ} \mathrm{C}$. Subsequent dilutions were made in RPMI-1640 (Hyclone, Logan, UT, USA). The maximal concentration of DMSO did not exceed $0.1 \%(\mathrm{v} / \mathrm{v})$ in the treatment range, where there was no influence on the cell growth. All other chemicals with the highest purity available were from Sigma-Aldrich Co. (St. Louis, MO, USA).

Cell culture. HCT116 human colon cancer cells (p53 wildtype) were obtained from American Type Culture Collection (Mansssas, VA, USA) and were cultured in RPMI-1640 (Hyclone) supplemented with $10 \%$ fetal bovine serum (FBS, Hyclone), $2 \mathrm{mM}$ glutamine (Sigma-Aldrich), $100 \mathrm{U} / \mathrm{ml}$ penicillin (Hyclone), and $100 \mu \mathrm{g} / \mathrm{ml}$ streptomycin (Hyclone) at $37^{\circ} \mathrm{C}$ in a humidified $5 \% \mathrm{CO}_{2}$.

Cell viability assay. Cell viability was determined by MTT assay. For the MTT assay, HCT116 cells were seeded in a 24-well culture plate at a density of $4 \times 10^{4}$ cells/well, cultured for $24 \mathrm{~h}$ in the growth media, and then treated with or without various reagents for the indicated concentrations. The cells were incubated with $0.5 \mathrm{mg} / \mathrm{ml} \mathrm{3-(4,5-dimethylthiazol-2-yl)-}$ 2,5-diphenyl tetrazolium bromide (MTT, Sigma-Aldrich) at $37^{\circ} \mathrm{C}$ for $2 \mathrm{~h}$. The formazan granules generated by the live cells were dissolved in DMSO, and the absorbance at $540 \mathrm{~nm}$ was monitored by using a multi-well reader.

Nuclear staining with Hoechst 33342. Cells were washed with phosphate-buffered saline (PBS) and fixed with $3.7 \%$ paraformaldehyde (Sigma-Aldrich) in PBS for $10 \mathrm{~min}$ at room temperature. Fixed cells were washed with PBS and stained with $4 \mu \mathrm{g} / \mathrm{ml}$ Hoechst 33342 for $20 \mathrm{~min}$ at room temperature. The cell were washed two more times with PBS and analyzed via a fluorescent microscope.

DNA fragmentation assay. Cells were lysed in a buffer, containing $5 \mathrm{mM}$ Tris- $\mathrm{HCl}(\mathrm{pH} 7.5), 5 \mathrm{mM}$ EDTA, and $0.5 \%$ Triton X-100, for $30 \mathrm{~min}$ on ice. Lysates were vortexed and cleared by centrifugation at $14,000 \mathrm{rpm}$ for $20 \mathrm{~min}$. Fragmented DNA in the supernatant was treated with RNase, followed by proteinase $\mathrm{K}$ digestion, phenol:chloroform:isoamyl alcohol mixture (25:24:1) extraction and isopropanol precipitation. DNA was separated through a $1.5 \%$ agarose gel, was stained with $0.1 \mu \mathrm{g} / \mathrm{ml}$ ethidium bromide, and was visualized by UV source.

Cell cycle analysis. The DNA content was measured following the staining of the cells with propidium iodide. The cells were treated under the appropriate conditions for $24 \mathrm{~h}$, subsequently trypsinized, washed once in cold PBS, and then fixed in $70 \%$ ethanol at $4{ }^{\circ} \mathrm{C}$ overnight. The fixed cells were pelleted and stained in cold propidium iodide (PI, Sigma-Aldrich) solution (50 $\mu \mathrm{g} / \mathrm{ml}$ in PBS) at room temperature for $30 \mathrm{~min}$ in the dark. Flow cytometry analysis was performed on a FACScan flow cytometry system (Becton-Dickinson, San Jose, CA, USA).

Caspase activity assay. The cells were harvested and washed with cold PBS. Total cells were lysed with the lysis buffer [40 mM Tris (pH 8.0), $120 \mathrm{mM}, \mathrm{NaCl}, 0.5 \%$ NP-40, $0.1 \mathrm{mM}$ sodium orthovanadate, $2 \mu \mathrm{g} / \mathrm{ml}$ aprotinin, $2 \mu \mathrm{g} / \mathrm{ml}$ leupeptin and $100 \mu \mathrm{g} / \mathrm{ml}$ phenymethylsulfonyl fluoride (PMSF)] at $4^{\circ} \mathrm{C}$ for $30 \mathrm{~min}$. Cell lysate protein $(100 \mu \mathrm{g})$ was mixed in assay buffer in a final volume of $100 \mu \mathrm{l}$, followed by addition of $10 \mu \mathrm{l}$ of $2 \mathrm{mM}$ of the substrate caspase- 8 (Z-IETD-pNA), caspase-9 (Ac-LEHD-pNA), or caspase-3 (Z-DEVD-pNA) for the respective caspase assay. The reaction mixture was incubated at $37^{\circ} \mathrm{C}$ for $30 \mathrm{~min}$ and liberated p-nitroaniline (pNA) was measured at $405 \mathrm{~nm}$ using a multi-well reader.

Preparation of cytosolic and nuclear protein extracts. The cells were washed with cold PBS and resuspended in Buffer A [10 mM HEPES (pH 7.9), 1.5 mM MgCl $2,10 \mathrm{mM} \mathrm{KCl,} 0.5 \mathrm{mM}$ DTT, $0.5 \mathrm{mM}$ PMSF and Protease inhibitor cocktail (SigmaAldrich)] and incubated on ice. After $15 \mathrm{~min}, 0.5 \%$ Nonidet $\mathrm{P}$ (NP)-40 was added to lyse the cells, which were vortexed for $10 \mathrm{sec}$. Cytosolic extracts were obtained after centrifuging at $12,000 \mathrm{rpm}$ for $60 \mathrm{sec}$ at $4^{\circ} \mathrm{C}$. Nuclear extracts were resuspended in Buffer C [20 mM HEPES (pH 7.9), $1.5 \mathrm{mM} \mathrm{MgCl}_{2}$, 


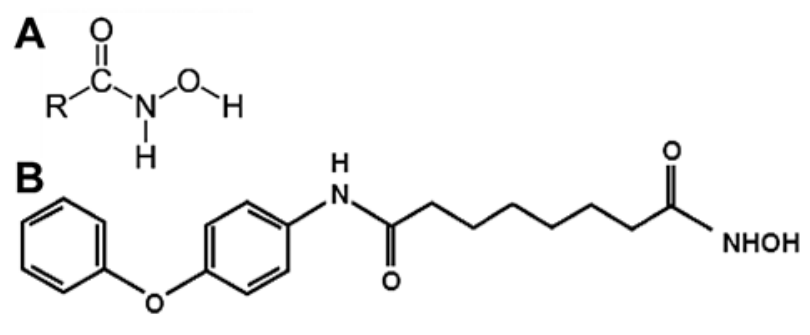

Figure 1. Chemical structures of hydroxamic acid (A) and MHY218 (B). $\mathrm{R}$, an organic residue.

$300 \mathrm{mM} \mathrm{NaCl}, 0.2 \mathrm{mM}$ EDTA, $20 \% \mathrm{v} / \mathrm{v}$ glycerol, $0.5 \mathrm{mMDTT}$, $0.5 \mathrm{mM}$ PMSF and protease inhibitor cocktail] and incubated on ice for $20 \mathrm{~min}$ with gentle vortexing every $5 \mathrm{~min}$. Nuclear cell extracts were recovered after centrifugation for $10 \mathrm{~min}$ at $12,000 \mathrm{rpm}$ at $4^{\circ} \mathrm{C}$. Protein concentration was determined by Bradford protein assay reagent (Bio-Rad, Hercules, CA, USA).

Western blot analysis. The cells were treated with the appropriate conditions, harvested, and washed with cold PBS. Total cells lysates were lysed in lysis buffer [40 mM Tris ( $\mathrm{pH} 8.0)$, $120 \mathrm{mM}, \mathrm{NaCl}, 0.5 \% \mathrm{NP}-40,0.1 \mathrm{mM}$ sodium orthovanadate, $2 \mu \mathrm{g} / \mathrm{ml}$ aprotinin, $2 \mu \mathrm{g} / \mathrm{ml}$ leupeptin and $100 \mu \mathrm{g} / \mathrm{ml} \mathrm{PMSF]}$. The supernatant was collected and protein concentrations were then measured with protein assay reagents (Pierce, Rockford, IL, USA). Protein extracts were denatured by boiling at $100^{\circ} \mathrm{C}$ for $5 \mathrm{~min}$ in sample buffer $(0.5 \mathrm{M}$ Tris- $\mathrm{HCl}$, pH 6.8, 4\% SDS, $20 \%$ glycerol, $0.1 \%$ bromophenol blue, $10 \% \beta$-mercaptoethanol). Equal amount of the total proteins were subjected to 6-15\% SDS-PAGE and transferred to PVDF. The membranes were blocked with 5\% non-fat dry milk in Tris-buffered saline with Tween-20 buffer (TBS-T) $(20 \mathrm{mM}$ Tris, $100 \mathrm{mM} \mathrm{NaCl}, \mathrm{pH} 7.5$ and $0.1 \%$ Tween-20) for $1 \mathrm{~h}$ at room temperature. Then, the membranes were incubated overnight at $4^{\circ} \mathrm{C}$ with primary antibodies. The membranes were washed once for $10 \mathrm{~min}, 4$ times with TBS-T buffer and incubated for $1 \mathrm{~h}$ with horseradish peroxidase-conjugated anti-rabbit or anti-mouse immunoglobin (Santa Cruz Biotechnology Inc., Santa Cruz, CA, USA). The membranes were washed again for $10 \mathrm{~min}, 4$ times with TBS-T buffer. Antigen-antibody complexes were detected by the enhanced chemiluminescence (ECL) detection system (Amersham Biosciences Corp., Little Chalfont, Bucks, UK).

Reverse transcriptase-polymerase chain reaction (RT-PCR) analysis. For RT-PCR analysis, total RNA was extracted from cultured cells using a TRIzol reagent as described by the manufacturer (Invitrogen), PCR amplification cDNA was prepared using a Bioneer RT/PCR PreMix containing $1 \mathrm{U}$ Taq DNA polymerase, $250 \mu \mathrm{M}$ dNTPs, $10 \mathrm{mM}$ Tris- $\mathrm{HCl}$, $40 \mathrm{mM} \mathrm{KCl}, 1.5 \mathrm{mM} \mathrm{MgCl}_{2}$ (Bioneer, Korea). The assay was carried out in a $20 \mu \mathrm{l}$ reaction mixture containing $1.0 \mu \mathrm{g}$ of total RNA, 30 pmol of each primer, $1 \mu \mathrm{g}$ Oligo dT (Bioneer), using a PCR Thermal Cycler Dice Takara TP600 (Takara, Otsu, Japan). The mRNAs were amplified with the primers indicated in Table I. GAPDH served as an internal control. The cycling conditions were as follows: cDNA synthesis at
Table I. Primer sequences for RT-PCR.

\begin{tabular}{lll}
\hline Gene & & Sequence of primers $\left(5^{\prime} \rightarrow 3^{\prime}\right)$ \\
\hline Cox-2 & $\begin{array}{l}\text { Sense } \\
\text { Antisense }\end{array}$ & AGA TCA TCT CTG CCT GAG TAT CTT \\
GAPDH & Sense & CGG AGT CAA CGG ATT TGG TCG TAT \\
& Antisense & AGC CTT CTC CAT GGT GGT GAA GAC \\
\hline
\end{tabular}

$42^{\circ} \mathrm{C}$ for $60 \mathrm{~min}$, RTase inactivation at $94^{\circ} \mathrm{C}$ for $5 \mathrm{~min}, 1 \mathrm{x}$ denaturation $\left(94^{\circ} \mathrm{C}\right.$ for $\left.30 \mathrm{sec}\right), 30 \mathrm{x}$ annealing $\left(58^{\circ} \mathrm{C}\right.$ for $30 \mathrm{sec})$, and $1 \mathrm{x}$ extension $\left(72^{\circ} \mathrm{C}\right.$ for $\left.1 \mathrm{~min}\right)$ for 30 cycles. PCR products were analyzed by electrophoresis on $1 \%$ agarose gel (Bio Basic Inc., Markham, Ontario, Canada) in the presence of ethidium bromide, and were visualized with a UV transilluminator (MultiImage ${ }^{\mathrm{TM}}$ Light Cabinet, Alpha Innotech Co., San Leandro, CA, USA).

Luciferase reporter assay for $N F-\kappa B$ activity. The activity of NF- $\kappa B$ was examined using a luciferase plasmid DNA, pTAL-NF- $\kappa B$ that contains a specific binding sequence for NF- $\kappa B$ (BD Biosciences Clontech, CA, USA). Transfection was carried out using TransIT-LT1 transfection reagent (Promega, Madison, WI, USA). Briefly, HCT116 cells were seeded in 6-well plates. When cultured cells reached $\sim 50 \%$ confluence, cells were treated with $2 \mu \mathrm{g}$ DNA/ $6 \mu$ transfection complexes in a total volume of media with $2 \mathrm{ml}$ for $24 \mathrm{~h}$. Subsequently, various concentrations of MHY218 were treated and incubated for $1 \mathrm{~h}$, and then $10 \mathrm{ng} / \mathrm{ml}$ TNF- $\alpha$ was treated and incubated for $6 \mathrm{~h}$. Cells were washed with PBS and added by Stead-Glo Luciferase Assay System (Promega) to the plate. Luciferase activity was measured by a luminometer (GENious, Tecan, Salzburg, Austria). The obtained raw luciferase activities were normalized by protein concentration in each well.

Zymography. Zymography was used to semiquantitatively determine the gelatinolytic activity of matrix metalloproteinase-9 (MMP-9) secreted into culture media. Equal amount of conditioned culture media from equal number cells were applied to SDS-PAGE containing $0.25 \%$ gelatin. The gel was incubated with the renaturing buffer $(2.5 \%$ Triton X-100) with gentle agitation for $30 \mathrm{~min}$ at room temperature. The gel was washed once for $10 \mathrm{~min}, 2$ times with distilled water and incubated overnight at $37^{\circ} \mathrm{C}$ with the Developing buffer [1 M Tris- $\left.\mathrm{HCl}(\mathrm{pH} 7.5), 1 \mathrm{M} \mathrm{CaCl}_{2}, 10 \% \mathrm{NaN}_{3}, 1 \mathrm{M} \mathrm{NaCl}\right]$. The gel was stained with $0.5 \%$ (w/v) Coomassie Blue R-250 for $30 \mathrm{~min}$ at room temperature and then destained with the destaining solution (methanol:acetic acid:distilled water $=50: 10: 40$ ). Areas of protease activity appeared as clear bands against a dark blue background where the protease had digested the substrate. The product of zymography was visualized with a White light transilluminator (BioSpectrum ${ }^{\circledR}$ Imaging System, Upland, CA, USA).

Statistical analysis. Results were expressed as the mean \pm SD of three separate experiments and analyzed by Student's t-test. Means were considered significantly different at $\mathrm{p}<0.05$ or $\mathrm{p}<0.01$. 


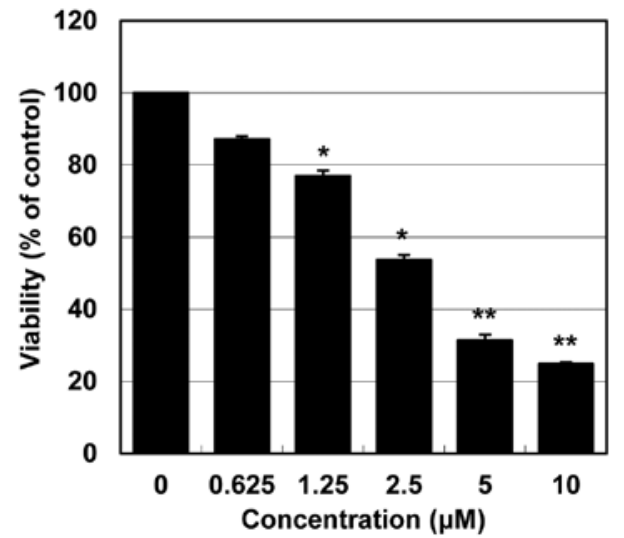

Figure 2. Effect of MHY218 on cell viability of HCT116 cells. One day after seeding, cells were treated with increasing concentration of MHY218 synthetics for $24 \mathrm{~h}$. Proliferation was measured by using the MTT assay. The results are expressed as mean $\pm \mathrm{SD}(\mathrm{n}=6)$ and as a percentage of vehicle-treated control. ${ }^{*} \mathrm{p}<0.05$ and ${ }^{* *} \mathrm{p}<0.01$ compared to control and MHY218-treated cells.

\section{Results}

MHY218 inhibits the growth of HCT116 cells. To investigate the effects of MHY218 on the viability of HCT116 cells, the MTT assay was performed. As shown in Fig. 2. MHY218 showed concentration-dependent cytotoxicity on HCT116 cells. The $\mathrm{IC}_{50}$ value of MHY218 on HCT116 cells was $\sim 3.0 \mu \mathrm{M}$.

MHY218 modulates the cell cycle in HCT116 cells. To investigate whether the inhibition of HCT116 cell growth was mediated, at least in part, by regulating the cell cycle, flow cytometry analysis of PI-stained HCT116 nuclei was performed. This flow cytometry analyses data showed that MHY218 treatment induced the accumulation of cells in $\mathrm{G} 2 / \mathrm{M}$ phase of the cell cycle, with the occurrence of sub-G1 peak, indicating DNA degradation through either necrosis or apoptosis (Fig. 3A). G2/M phase arrest by MHY218 treatment reached the maximum percentage at $24 \mathrm{~h}$. After $24 \mathrm{~h}$ incubation with different concentrations of MHY218, the population of the cells at the G2/M phase increased from $27.89 \%$ (vehicle alone) to $57.07 \%(10 \mu \mathrm{M}$ MHY218) (Fig. 3A). As shown in Fig. 3A, the increase of cell population in $\mathrm{G} 2 / \mathrm{M}$ phase consequently occurred with the decrease in G0/G1 cells as compared to those of control. In addition, we also observed the appearance of the peak corresponding to a population of cells with sub-G1 DNA content. This peak represented MHY218-induced DNA degradation either by necrosis or by apoptosis in HCT116 cells. After $24 \mathrm{~h}$ incubation of $10 \mu \mathrm{M}$ MHY218, as shown in Fig. 3A, the fractions of sub-G1 peak increased from $3.55 \%$ (vehicle alone) to $19.72 \%$ (10 $\mu \mathrm{M}$ MHY218). These result supported that the MHY218 treatment for $24 \mathrm{~h}$ mainly induced the inhibition of cell growth via G2/M phase arrest in the cell cycle.

MHY218 modulates cell cycle regulatory proteins in HCT116 cells. To assess the effect of MHY218 on the intracellular

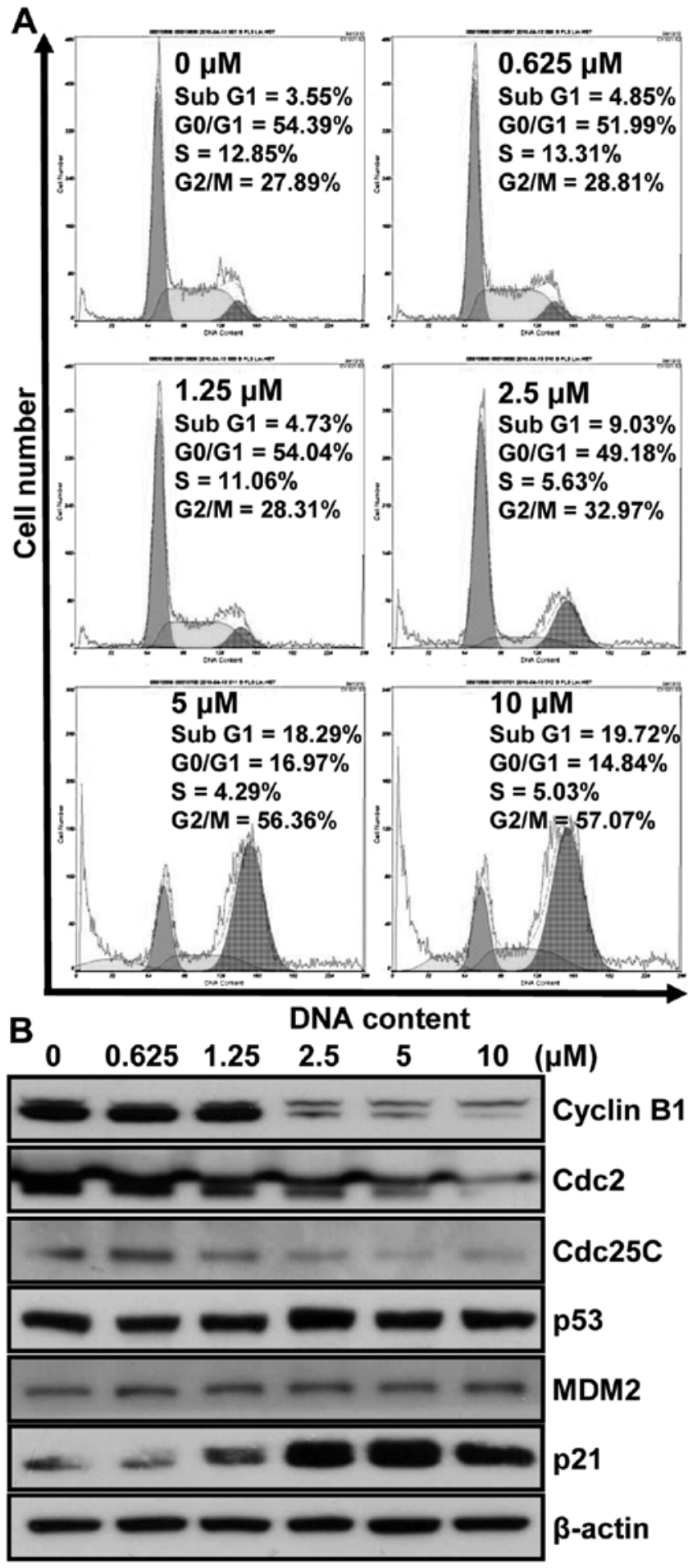

Figure 3. Effects of MHY218 on the cell cycle and the levels of cell cycle regulator proteins in HCT116 cells. (A) Exponentially growing cells at $60-70 \%$ confluence were treated for $24 \mathrm{~h}$ with the indicated concentrations of MHY218. The percentages of cells in sub-G1, G0/G1, S or G2/M phases of cell cycle are indicated within each histogram. (B) HCT116 cells were treated with indicated concentrations of MHY218 for $24 \mathrm{~h}$, collected, lysed and then cellular proteins were separated and immunoblotted. The membranes were probed with indicated antibodies and ECL detection. Representative results from more than three independent experiments are shown. Actin was used as a loading control.

protein expression levels of $\mathrm{G} 2 / \mathrm{M}$ phase in the cell cycle, we performed western blot analysis. As shown in Fig. 3B, the expression levels of cyclin B1, Cdc25C and Cdc2 were decreased 


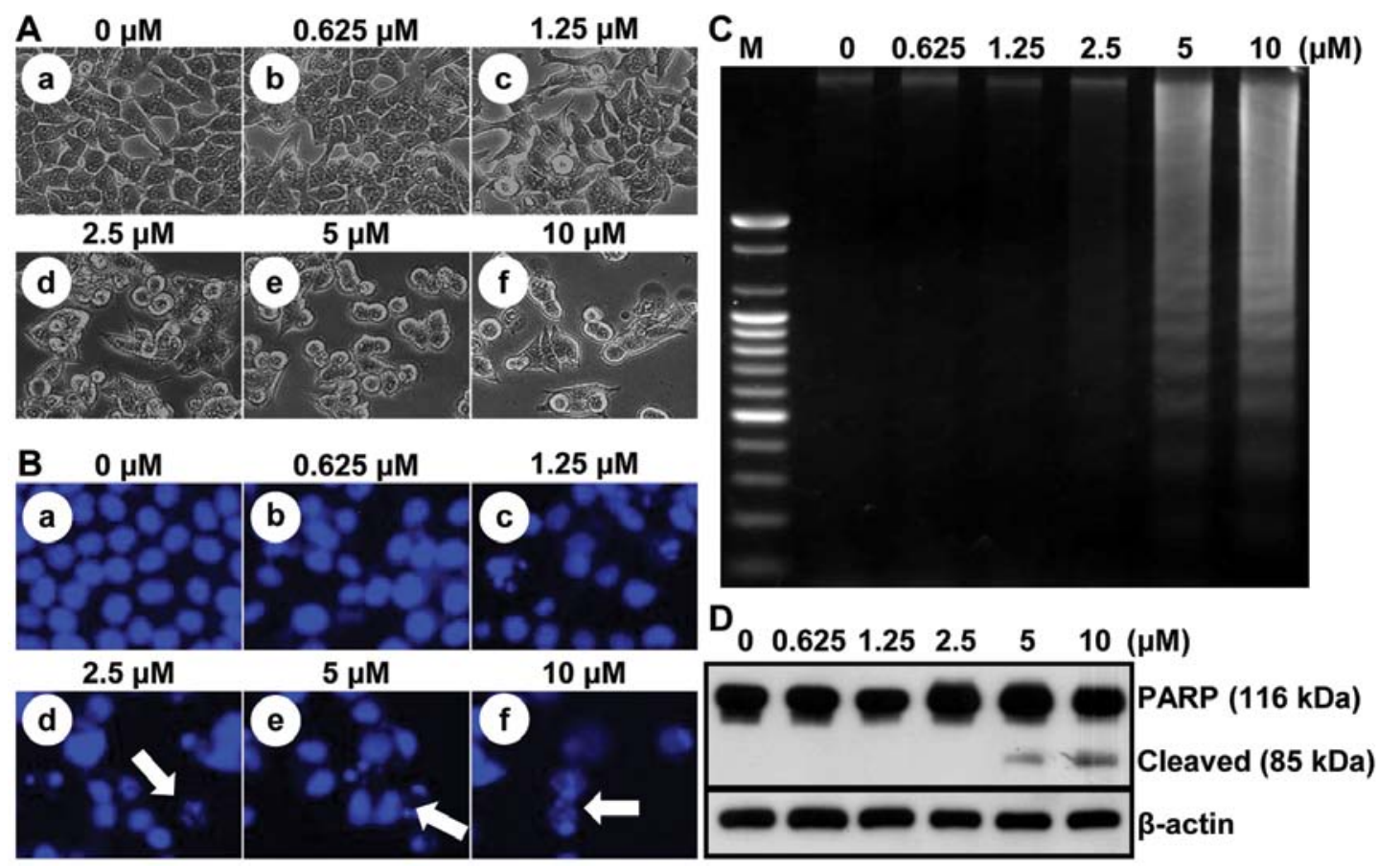

Figure 4. Induction of apoptosis in HCT116 cells by MHY218. (A) HCT116 cells were treated for $24 \mathrm{~h}$ with the indicated concentrations of MHY218 and morphological changes were observed by phase contrast microscopy at $\mathrm{x} 400$ magnification. (B) Stained nuclei with fluorescent microscopic dye, Hoechst 33342, were then photographed with a fluorescent microscope using a blue filter at $\mathrm{x} 400$ magnification. Arrows, apoptotic cells. (C) HCT116 cells were treated for $24 \mathrm{~h}$ with the indicated concentrations of MHY218. DNA was extracted and analyzed by $1.5 \%$ agarose gel electrophoresis in the presence of EtBr. A representative blot is shown from three independent experiments. M, marker. (D) To detect degradation of PARP, HCT116 cells were treated with indicated concentrations of MHY218 for $24 \mathrm{~h}$, collected, lysed and then cellular proteins were separated and immunoblotted. The membranes were probed with PARP $(116 \mathrm{kDa})$. Proteins were visualized using the ECL detection system. Representative results from three independent experiments are shown. Actin was used as a loading control.

by MHY218 treatment as compared to the basal levels in a concentration-dependent manner. The induction of $\mathrm{p} 21^{\text {WAFI/CIPI }}$ causes subsequent arrest in the G0/G1 or G2/M phase of the cell cycle by binding of the cyclin-cyclin-dependent kinase (CDK) complex. Thus further studies were performed to elucidate whether p21 $1^{\text {WAFI/CIPI }}$ was induced by the MHY218 treatment either via a 53-dependent or a p53-independent pathway in HCT116 cells. The results show that p53 was not significantly changed and $\mathrm{p} 21^{\text {WAFI/CIPI }}$ was increased without the change in the level of MDM2 by MHY218 treatment in HCT116 cells (Fig. 3B). Therefore, these results suggest that MHY218 treatment induces $\mathrm{G} 2 / \mathrm{M}$ phase arrest in cell cycle by downregulating expressions of cyclin, CDKs, and induction of $\mathrm{p} 21^{\text {WAFI/CIPI }}$ via p53-independent pathway.

MHY218 induces morphological changes and apoptosis in HCT116 cells. To assess whether there are any morphological changes in MHY218-treated HCT116 cells, we examined the cells by phase-contrast light microscopy after $24 \mathrm{~h}$ of incubation with or without MHY218. Under the light microscope, untreated HCT116 cells spread regularly in the culture plate and grew to near confluence (Fig. 4Aa). In contrast, MHY218-treated HCT116 cells were shrunken and changed to round form. Additionally, cell numbers were decreased in a concentration-dependent manner (Fig. 4Ab-f). To investigate whether the growth inhibitory effects of MHY218 were due to the induction of apoptosis in HCT116 cells, the morphological changes were assessed with Hoechst 33342 staining.
As shown in Fig. 4B, nuclei with chromatin condensation and formation of apoptotic bodies, which are characteristics of apoptosis, were seen in cells cultured with MHY218 in a concentration-dependent manner (Fig. 4Bb-4f), whereas the control cells maintained nuclear structure intact (Fig. 4Ba). We also analyzed whether DNA fragmentation, another hallmark of apoptosis, was induced by MHY218 treatment on HCT116 cells. Following agarose gel electrophoresis of HCT116 cells treated with MHY218 for $24 \mathrm{~h}$, a typical ladder pattern of internucleosomal fragmentation was observed in a concentration-dependent manner (Fig. 4C). Polypeptide degradation, including poly(ADP-ribose) polymerase (PARP), was examined to see the possible involvement of apoptosis-associated protease activity during the growth inhibition of the colon cancer cells. PARP cleavage was evident by the appearance of the p85 PARP cleavage fragment (Fig. 4D) and clearly observed in the $5 \mu \mathrm{M}$ and $10 \mu \mathrm{M}$ of MHY218 treatment.

MHY218 modulates the expression levels of apopotosisrelated proteins in HCT116 cells. To determine whether the expression levels of apoptosis-related proteins were modulated by MHY218, western blot analysis was performed. The expression level of Bax protein was markedly upregulated, but Bcl-2 was downregulated in a concentration-dependent manner (Fig. 5A). The Bax/Bcl-2 ratio was also significantly increased with increase of MHY218 concentration (Fig. 5B). These data suggest that MHY218 induces apoptosis by the 

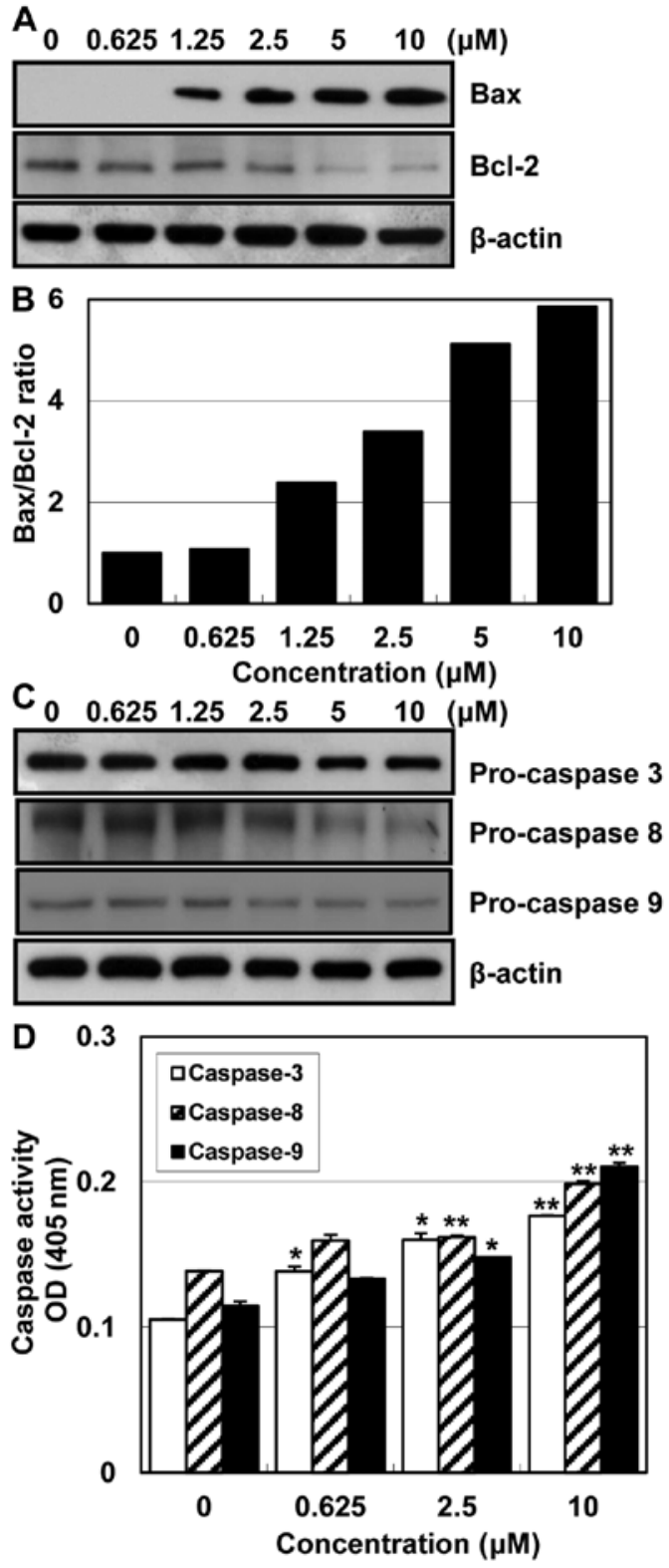

Figure 5. Effects of MHY218 on Bax/Bcl-2 ratio and caspase activation in HCT116 cells. (A) HCT116 cells were treated with variable concentrations of MHY218 for $24 \mathrm{~h}$ and total cell lysates were prepared and immunoblotted. The membranes were detected with antibodies against Bax and Bcl-2 and ECL detection. Representative results from three independent experiments are shown. Actin was used as a loading control. (B) Bax/ Bcl-2 ratio is presented in the bar graphs. (C) HCT116 cells were treated with indicated concentrations of MHY218 for $24 \mathrm{~h}$, collected, lysed and then cellular proteins were separated and immunoblotted. The membranes were probed with pro-caspase-3, -8 and -9 . Proteins were visualized using the ECL detection system. Representative results from three independent experiments are shown. Actin was used as a loading control. (D) Cell lysates from HCT116 cells treated with MHY 218 for $24 \mathrm{~h}$ were assayed for in vitro caspase-3, -8 and -9 activity using Z-DEVD-pNA, Z-IETD-pNA and Ac-LEHD-pNA, respectively, as substrates at $37^{\circ} \mathrm{C}$ for $1 \mathrm{~h}$. The released fluorescent products were measured. The data represent the mean \pm SD values of three independent experiments. The significance was determined by Student's t-test ( ${ }^{*} \mathrm{p}<0.05$ and ${ }^{* *} \mathrm{p}<0.01$ vs. vehicle-treated control cells). OD, optical density.

alterations in expression levels of $\mathrm{Bax} / \mathrm{Bcl}-2$ protein. The expression levels of pro-caspase-3, -8 and -9 were decreased, indicating the activation of these caspases (Fig. 5C). In an

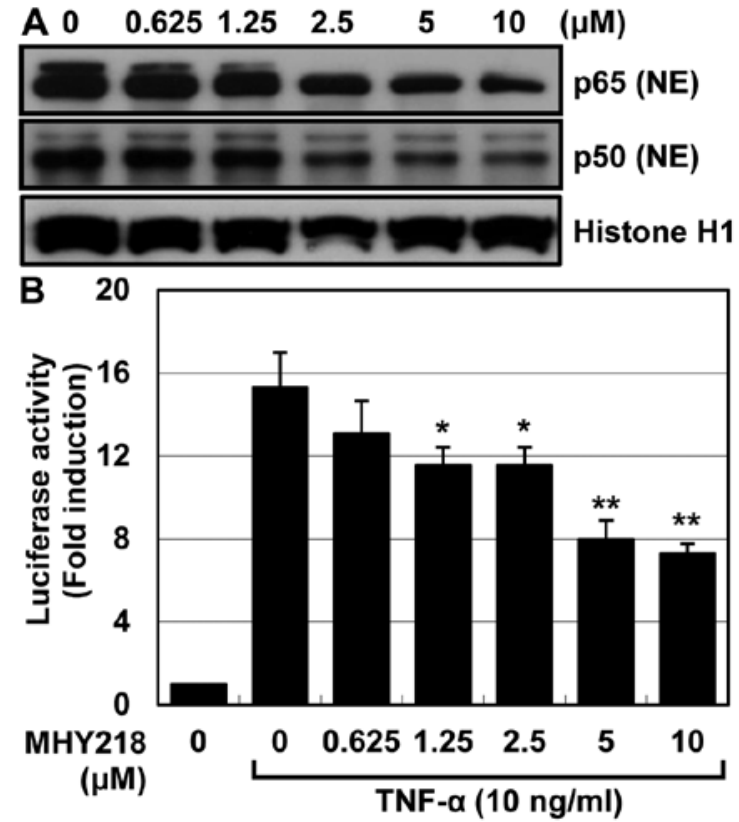

Figure 6. Effect of MHY218 on NF- $\kappa \mathrm{B}$ translocation and TNF- $\alpha$ induced $\mathrm{NF}-\kappa \mathrm{B}$ activity in HCT116 cells. (A) HCT116 cells were treated with variable concentrations of MHY218 for $24 \mathrm{~h}$ and total cell lysates were prepared and immunoblotted. The membranes were detected with antibodies against p50 and p65 in the nuclear extract and ECL detection. Representative results from three independent experiments are shown. Histone H1 was used as a loading control. NE, nucleus extract. (B) At 24 h post-transfection with $\mathrm{NF}-\kappa \mathrm{B}$ luciferase plasmid, HCT116 cells were treated with variable concentrations of MHY218 and incubated for $1 \mathrm{~h}$ and then TNF- $\alpha$ (10 ng/ $\mathrm{ml}$ ) was treated and incubated for $6 \mathrm{~h}$. Luciferase activity was measured by a luminometer. The obtained raw luciferase activity was normalized by protein concentration in each well. Results are expressed as percentages of the vehicle-treated control $\pm \mathrm{SD}$ of triplicate experiments. The significance was determined by Student's t-test $\left(^{*} \mathrm{p}<0.05\right.$ and ${ }^{* *} \mathrm{p}<0.01$ compared with TNF- $\alpha$ treated cells)

attempt to further characterize the mechanisms of apoptosis, the activity of caspase- $3,-8$ and -9 was determined by colorimetric assay. The activity of caspase- $-3,-8$ and -9 was increased with the treatment of MHY218 in a concentration-dependent manner (Fig. 5D). These results, taken all together, imply that MHY218 seems to induce apoptosis through the internal and external pathway in HCT116 cells.

MHY218 modulates the expression levels of $N F-\kappa B, C O X-2$, MMP-9 and 5-LOX protein in HCT116 cells. NF- $\kappa \mathrm{B}$ regulates the expression of a wide variety of genes involved in tumor cell growth and survival. We examined whether MHY218 has the potential to inhibit NF- $\kappa \mathrm{B}$ activation in MHY218treated HCT116 cells. After $24 \mathrm{~h}$ exposure with the indicated concentration of MHY218, the levels of nuclear NF- $\kappa \mathrm{B}$ p65 and $N F-\kappa B$ p50 were examined, with western blot analysis, because the nuclear translocation of the $N F-\kappa B$ subunits p65 and p50 is essential for NF- $\mathrm{NB}$ activation. As shown in Fig. 6A, treatment with MHY218 decreased nuclear translocations of p65 and p50, the functionally active subunits of $\mathrm{NF}-\kappa \mathrm{B}$, to the nucleus, in a concentration-dependent manner. Next to determine the effect of MHY218 on the TNF- $\alpha$ induced $\mathrm{NF}-\kappa \mathrm{B}$ transcriptional activity, HCT116 cells were transiently transfected with the NF- $\mathrm{B}$-regulated luciferase 


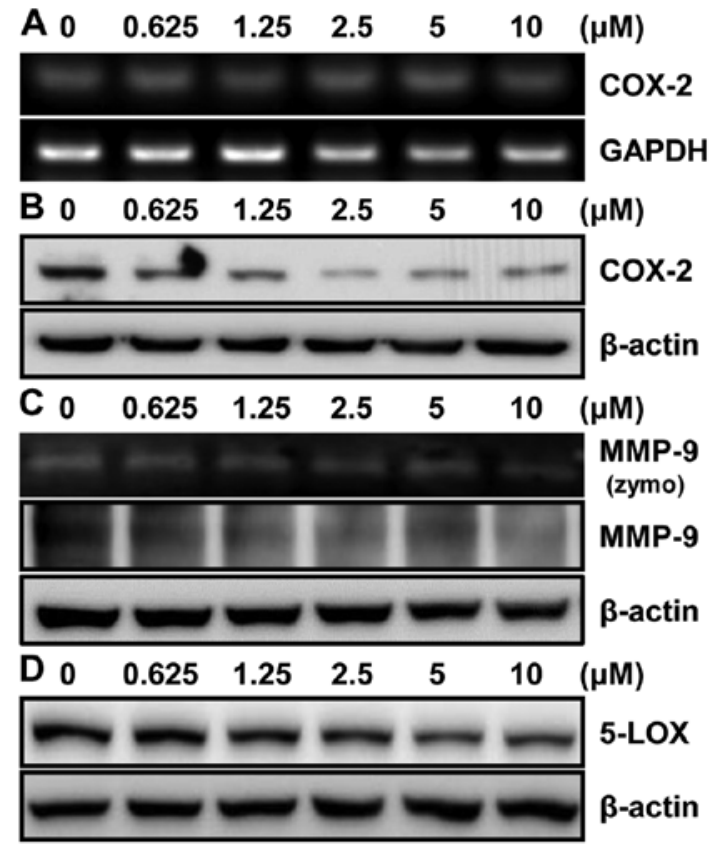

Figure 7. Effect of MHY218 on the levels of COX-2, MMP-9 and 5-LOX in HCT116 cells. (A) After $24 \mathrm{~h}$ incubation with MHY218, total RNAs were isolated and reverse-transcribed. The resulting cDNAs were subjected to PCR with COX-2 primers and the reaction products were subjected to electrophoresis in a $1 \%$ agarose gel and visualized by EtBr staining. GAPDH was used as a loading control. (B) The cells were treated with variable concentrations of MHY218 for $24 \mathrm{~h}$. Total cell lysates were prepared and subjected to $10 \%$ SDS-PAGE and electrophoretically transferred to PVDF membranes. Western blot analysis was conducted with COX-2 antibody and ECL kits. (C) Conditioned medium was collected from cultures following $24 \mathrm{~h}$ and analyzed by gelatin zymography (zymo). Western blot analysis was conducted with MMP-9 antibody and ECL kits. (D) In a parallel experiment, western blot analysis was conducted with 5-LOX antibody and ECL kits. Representative results from three independent experiments are shown. Actin was used as a loading control.

reporter construct, and the transfected cells were then stimulated with TNF- $\alpha$ alone or with a combination of TNF- $\alpha$ and MHY218. As shown in Fig. 6B, MHY218 significantly suppressed TNF- $\alpha$-induced activation of NF- $\mathrm{KB}$ as compared to untreated cells. These data indicated that MHY218 treatment resulted in a significant inhibition of NF- $\mathrm{kB}$ activation.

To further investigate the effect of MHY218 on expression level of the COX-2 protein, an NF- $\mathrm{\kappa B}$ downstream target gene, in HCT116 cells, the RT-PCR and western blot analyses showed no change in COX-2 mRNA (Fig. 7A) but a significant decrease in COX-2 protein expression after MHY218 treatment in a concentration-dependent manner (Fig. 7B). These data suggested that the inhibition of the COX-2 expression is consistent with the results that MHY218 inhibited the NF- $\mathrm{kB}$ activation. We next examined the effect of MHY218 on MMP-9 activity in HCT116 cells. Gelatin zymography showed that MMP-9 activity was significantly inhibited by MHY218 in a concentration-dependent manner (Fig. 7C). In order to determine the MMP-9 protein level in cells after treatment with MHY218, western blot analysis was performed. Being consistent with the observed alteration of activity, MMP-9 protein expression was significantly reduced in HCT116 cells treated with MHY218 in a concentration-dependent manner (Fig. 7C). Another downstream target gene of NF- $\kappa \mathrm{B}$ is 5-lipoxygenase
(5-LOX). We next examined the effect of MHY218 on 5-LOX protein level in HCT116 cells. 5-LOX protein level was also significantly reduced in HCT116 cells treated with MHY218 in a concentration-dependent manner (Fig. 7D). These data suggested that MHY218 inhibited TNF- $\alpha$-induced NF- $\mathrm{BB}$ activation through the suppression of nuclear translocation of NF- $\mathrm{KB}$, leading to reduced expression of NF- $\mathrm{BB}$-regulated gene products.

\section{Discussion}

This study was conducted to investigate the effects of MHY218 on HCT116 human colon cancer cells. MHY218 induced cell cycle arrest and apoptosis in HCT116 human colon cancer cells. MHY218 also modulated the activity of NF- $\kappa \mathrm{B}$ and downregulated the expression levels of COX-2, MMP-9 and 5-LOX protein in HCT116 cells.

The treatment of HCT116 cells with MHY218 resulted in growth inhibition concentration-dependently. Flow cytometric analysis revealed that MHY218 induced G2/M phase arrest. Different classes of cyclins and their CDK control cell cycle progression. G2/M transition provides an effective checkpoint in the cell cycle progression that is regulated by cyclin B1, Cdc2 and Cdc25C (15). In this study, treatment of HCT116 cells with MHY218 resulted in arrest of cells in G2/M phase and is associated with a decrease in the protein levels of cyclin $\mathrm{B} 1, \mathrm{Cdc} 2$ and $\mathrm{Cdc} 25 \mathrm{C}$.

p $21^{\text {WAFI/CIPI }}$, a cyclin-dependent kinase inhibitor, is commonly associated with the G1 checkpoint and G2/M phase, its association with inhibiting the expression of the Cdc2/cyclin B1 complex has also been demonstrated $(16,17)$. p21 $1^{\text {WAFI/CIPI }}$ transcription can be regulated through p53-dependent (18) and p53-independent pathways (19). In the present study, the protein level of p53 was not significantly increased, whereas p21 $1^{\text {WAFI/CIPI }}$ was increased without a change on the expression of MDM2 by MHY218 in HCT116 cells. These results suggested that MHY218 activated p21 ${ }^{\text {WAFI/CIPI }}$ expression and that this induced $\mathrm{G} 2 / \mathrm{M}$ phase arrest of the p53-independent pathway. Therefore, the upregulation of $\mathrm{p} 21^{\text {WAFI/CIPI }}$, and the downregulation of cyclin B1, Cdc2 and Cdc25C may be one of the molecular mechanisms by which MHY218 inhibited HCT116 cells growth and induced cell cycle arrest.

The treatment of MHY218 also induced apoptosis as demonstrated by the formation of apoptotic bodies and DNA fragmentation. Apoptosis (programmed cell death), is an important process requited for homeostasis (20). Apoptosis occurs through two broad pathways: the intrinsic pathway (the mitochondrial pathway) and extrinsic pathway (the death receptor pathway) (21). Caspases are key players in the extrinsic pathway. Another group of key players in the intrinsic pathway of apoptosis is the Bcl-2 family, which consists of $>20$ members of pro-apoptotic proteins (including Bax, Bak, Bok, $\mathrm{Bad}$ and Bid), and anti-apoptotic proteins (including Bcl-2, $\mathrm{Bcl}-\mathrm{X}_{\mathrm{L}}, \mathrm{Mcl}-1$ and Bfl-1/A1) (22).

The activation of effector caspase-3, in response to MHY218 treatment also resulted in cleavage of PARP in HCT116 cells. The ratio between Bcl-2 and Bax has been suggested as a primary event in determining the susceptibility to apoptosis through maintaining the integrity of the mitochondria and inhibiting the activation of caspase cascade 
(23). In this study, MHY218 treatment resulted in a significant increase in pro-apoptotic protein Bax and decrease in antiapoptotic protein Bcl-2 resulting in a shift in $\mathrm{Bax} / \mathrm{Bcl}-2$ ratio in favor of apoptosis. MHY218 treatment also increased the activation of initiator caspase- 8 and -9 and the downstream effector caspase-3 (24).

Certain chemopreventive agents for CRC, such as aspirin and other non-steroidal anti-inflammatory drugs (NSAIDs), have been shown to induce apoptosis through a suppression of $\mathrm{NF}-\kappa \mathrm{B}$ activation (25). NF- $\kappa \mathrm{B}$ acts as the 'first responder' to various types of cellular stress, such as free radicals, cytokines, ultraviolet radiation and bacterial components. It plays an important role in inflammation and carcinogenesis by regulating the expression of downstream target genes, including COX-2 (26), MMP-9 (27) and 5-LOX (28). The present study investigated the effect of MHY218 on the NF- $\kappa$ B pathway. Treatment of MHY218 to HCT116 cells resulted in inhibition of nuclear translocation of NF- $\kappa \mathrm{B}$ concentration-dependently. NF- $\kappa \mathrm{B}$ transcription factors can block apoptosis induced by TNF- $\alpha$ (29). TNF- $\alpha$ normally has less or no cytotoxic effect unless $\mathrm{NF}-\kappa \mathrm{B}$ activation or protein synthesis is blocked (30). In line with this, luciferase reporter assay revealed significant suppression of TNF- $\alpha$-induced $\mathrm{NF}-\kappa \mathrm{B}$ transcriptional activity in MHY218-treated HCT116 cells in a concentration-dependent manner.

COX-2 is the inducible form of cyclooxygenase that catalyzes the rate limiting step in prostaglandin synthesis from arachidonic acid and plays an important role in cancer and tumor promotion (31). It has been suggested that COX-2 induction mediated by $\mathrm{NF}-\kappa \mathrm{B}$ pathway could lead to malignant cell proliferation and invasion (32). These carcinogenic effect of COX-2 can be reversed by NSAIDs, elucidating the important of COX-2 inhibition in cancer therapy (33). It has been shown to inhibit COX-2 expression by repressing degradation of the inhibitory unit inhibitor $\mathrm{I} \kappa \mathrm{B} \alpha$ and hindering the nuclear translocation of the functionally active subunit of $\mathrm{NF}-\kappa \mathrm{B}$, thereby blocking improper $\mathrm{NF}-\kappa \mathrm{B}$ activation (34). The western blot analysis data also revealed that treatment of cells with MHY218 markedly inhibited COX-2, MMP-9 and 5-LOX protein expression in a concentration-dependent manner. However, RT-PCR analysis data showed no change in COX-2 mRNA. These results suggest that MHY218 may also be effective against colon cancer cells through suppression of $\mathrm{NF}-\kappa \mathrm{B}$ activity and $\mathrm{NF}-\kappa \mathrm{B}$ gene products.

In conclusion, MHY218 suppressed growth of HCT116 cells by causing G2/M cell cycle arrest and apoptosis. These results suggest that $\mathrm{MHY} 218$-induced cell cycle arrest and apoptosis are associated with inhibition of NF- $\mathrm{B}$ pathway. Taken together, these results suggested that the novel compound MHY218 may be useful in the chemoprevention and/or treatment of colon cancer.

\section{Acknowledgements}

This study was supported by the National Research Foundation of Korea (NRF) grant funded by the Korea government (MSIP) (No. 2009-0083538). We thank Aging Tissue Bank for providing research information.

\section{References}

1. Hwang HJ, Kang YJ, Hossain MA, et al: Novel dihydrobenzofuro[4,5-b][1,8]naphthyridin-6-one derivative, MHY-449, induces apoptosis and cell cycle arrest in HCT116 human colon cancer cells. Int J Oncol 41: 2057-2064, 2012.

2. National Cancer Information Center: Cancer incidence and death. Goyang. http://www.cancer.go.kr/mbs/cancer. Accessed July 21, 2013

3. Kelly C and Cassidy J: Chemotherapy in metastatic colorectal cancer. Surg Oncol 16: 65-70, 2007.

4. Hanahan D and Weinberg RA: The hallmarks of cancer. Cell 100: 57-70, 2000.

5. Sun SY, Hail N Jr and Lotan R: Apoptosis as a novel target for cancer chemoprevention. J Natl Cancer Inst 96: 662-672, 2004.

6. Aggarwal BB and Shishodia S: Suppression of the nuclear factorkappaB activation pathway by spice-derived phytochemicals: reasoning for seasoning. Ann NY Acad Sci 1030: 434-441, 2004.

7. Horst D, Budczies J, Brabletz T, Kirchner T and Hlubek F Invasion associated up-regulation of nuclear factor kappaB target genes in colorectal cancer. Cancer 115: 4946-4958, 2009.

8. Luo JL, Maeda S, Hsu LC, Yagita H and Karin M: Inhibition of NF-kappaB in cancer cells converts inflammation-induced tumor growth mediated by TNFalpha to TRAIL-mediated tumor regression. Cancer Cell 6: 297-305, 2004.

9. Nandy P, Lien EJ and Avramis VI: Inhibition of ribonucleotide reductase by a new class of isoindole derivatives: drug synergism with cytarabine (Ara-C) and induction of cellular apoptosis. Anticancer Res 19: 1625-1633, 1999.

10. Choudhary C, Kumar C, Gnad F, et al: Lysine acetylation targets protein complexes and co-regulates major cellular functions. Science 325: 834-840, 2009.

11. Walkinshaw DR and Yang XJ: Histone deacetylase inhibitors as novel anticancer therapeutics. Curr Oncol 15: 237-243, 2008.

12. Mottet $D$ and Castronovo V: Histone deacetylases: target enzymes for cancer therapy. Clin Exp Metastasis 25: 183-189, 2008.

13. Jeon HS, Ahn MY, Park JH, et al: Anticancer effects of the MHY218 novel hydroxamic acid-derived histone deacetylase inhibitor in human ovarian cancer cells. Int J Oncol 37: 419-428, 2010.

14. Park JH, Ahn MY, Kim TH, et al: A new synthetic HDAC inhibitor, MHY218, induces apoptosis or autophagy-related cell death in tamoxifen-resistant MCF-7 breast cancer cells. Invest New Drugs 30: 1887-1898, 2012.

15. Molinari M: Cell cycle checkpoints and their inactivation in human cancer. Cell Prolif 33: 261-274, 2000.

16. Niculescu AB, 3rd, Chen X, Smeets M, Hengst L, Prives C and Reed SI: Effects of p21(Cip1/Waf1) at both the G1/S and the $\mathrm{G} 2 / \mathrm{M}$ cell cycle transitions: $\mathrm{pRb}$ is a critical determinant in blocking DNA replication and in preventing endoreduplication. Mol Cell Biol 18: 629-643, 1998.

17. Baus F, Gire V, Fisher D, Piette J and Dulic V: Permanent cell cycle exit in $\mathrm{G} 2$ phase after DNA damage in normal human fibroblasts. EMBO J 22: 3992-4002, 2003.

18. el-Deiry WS, Tokino T, Velculescu VE, et al: WAF1, a potential mediator of p53 tumor suppression. Cell 75: 817-825, 1993.

19. Gartel AL and Tyner AL: Transcriptional regulation of the p21((WAF1/CIP1)) gene. Exp Cell Res 246: 280-289, 1999.

20. Iannolo G, Conticello C, Memeo L and De Maria R: Apoptosis in normal and cancer stem cells. Crit Rev Oncol Hematol 66: 42-51, 2008.

21. Lorenzo HK and Susin SA: Therapeutic potential of AIF-mediated caspase-independent programmed cell death. Drug Resist Updat 10: 235-255, 2007.

22. Guo B, Godzik A and Reed JC: Bcl-G, a novel pro-apoptotic member of the Bcl-2 family. J Biol Chem 276: 2780-2785, 2001.

23. Harris $\mathrm{MH}$ and Thompson CB: The role of the Bcl-2 family in the regulation of outer mitochondrial membrane permeability. Cell Death Differ 7: 1182-1191, 2000.

24. Lahiry L, Saha B, Chakraborty J, et al: Theaflavins target Fas/caspase- 8 and Akt/pBad pathways to induce apoptosis in p53-mutated human breast cancer cells. Carcinogenesis 31: 259-268, 2010.

25. Kopp E and Ghosh S: Inhibition of NF-kappa B by sodium salicylate and aspirin. Science 265: 956-959, 1994.

26. Spehlmann ME and Eckmann L: Nuclear factor-kappa B in intestinal protection and destruction. Curr Opin Gastroenterol 25: 92-99, 2009. 
27. Bond M, Fabunmi RP, Baker AH and Newby AC: Synergistic upregulation of metalloproteinase- 9 by growth factors and inflammatory cytokines: an absolute requirement for transcription factor NF-kappa B. FEBS Lett 435: 29-34, 1998.

28. Chopra A, Ferreira-Alves DL, Sirois P and Thirion JP: Cloning of the guinea pig 5-lipoxygenase gene and nucleotide sequence of its promoter. Biochem Biophys Res Commun 185: 489-495, 1992.

29. Nagaki M, Naiki T, Brenner DA, et al: Tumor necrosis factor alpha prevents tumor necrosis factor receptor-mediated mouse hepatocyte apoptosis, but not fas-mediated apoptosis: role of nuclear factor-kappaB. Hepatology 32: 1272-1279, 2000.

30. Wajant H, Pfizenmaier K and Scheurich P: Tumor necrosis factor signaling. Cell Death Differ 10: 45-65, 2003.

31. Mann JR and DuBois RN: Cyclooxygenase-2 and gastrointestinal cancer. Cancer J 10: 145-152, 2004.
32. Kim JH, Lee KW, Lee MW, Lee HJ, Kim SH and Surh YJ: Hirsutenone inhibits phorbol ester-induced upregulation of COX-2 and MMP-9 in cultured human mammary epithelial cells: NF-kappaB as a potential molecular target. FEBS Lett 580: 385-392, 2006.

33. Claria $\mathbf{J}$ and Romano $\mathrm{M}$ : Pharmacological intervention of cyclooxygenase-2 and 5-lipoxygenase pathways. Impact on inflammation and cancer. Curr Pharm Des 11: 3431-3447, 2005.

34. Surh YJ, Chun KS, Cha HH, et al: Molecular mechanisms underlying chemopreventive activities of anti-inflammatory phytochemicals: down-regulation of COX-2 and iNOS through suppression of NF-kappa B activation. Mutat Res 480-481: 243-268, 2001. 